\title{
Drying of coal fines assisted by ceramic sorbents
}

\author{
MJ van Rensburg, M Le Roux, QP Campbell
}

North-West University, Student, Masters Degree in Chemical Engineering, School of Chemical and Minerals Engineering, Private Bag X6001, Potchefstroom 2520, South Africa, +27 18299 4052, 21089906@nwu.ac.za

\begin{abstract}
It is proposed to introduce contact sorption drying as a method to reduce the moisture content in coal fines. The aim of this study was to investigate the possibility of drying fine and ultra-fine coal using porous ceramic as the moisture sorbent. The main focus of this report is to define how the air temperature, particle size variations and mixing ratio would influence the contact between coal and ceramic for effective moisture adsorption. Drying of coal fines assisted by ceramic sorbents proved to be a viable concept as the ceramic was able to not only reduce the moisture content of fine coal, but of ultra-fine coal as well. The larger surface area of smaller ceramics allowed for efficient contact and consequently higher dewatering rates. The addition of more ceramic resulted in better contact with the wet coal and reduced the operating time quite significantly. Improved contact between the coal and ceramic therefore proved to be the main driving force during adsorption drying.
\end{abstract}

Keywords: Alumina; Ceramic; Coal; Drying; Fines; Moisture; Sorbent; Sorption

\section{Introduction}

Mangena et al. (2003) estimated that about $12 \%$ of South Africa's mined coal can be classified as fine and ultra-fine coal. Due to its large surface area, the coal fine fraction retains the majority of the moisture in mined coal and can contain a moisture content of higher than $25 \%$ by weight (Le Roux, 2003). Compared to coarse coal, the fine and especially the ultra-fine fraction are far more difficult to dewater to an acceptable moisture content. As a result of the difficulty in dewatering, the fines are often dumped into discard dams or slurry ponds. Consequently these disposal methods leads to a series of environmental problems such as acid mine drainage, dust release, spontaneous combustion and it also occupies large areas of land. Aside from the environmental problems, the wasted coal fines have heating values comparable to the coarse coal fraction when dried (Reddick et al., 2007). It would then be sensible to investigate and implement cost effective and efficient drying methods to salvage the wasted fines and process the mined fine fraction. It is important to use coal wisely as it is the primary energy resource in South Africa (Fourie et al., 1980).

In fine coal processing the mechanical dewatering techniques are ineffective as these methods cannot reduce the moisture content to a desirable level. Dewatering of coal fines often relies strongly on thermal methods as coal fines are known to retain water (Le Roux \& Campbell, 2003). There are several conventional thermal drying methods, however not all of these systems are ideal in terms of energy consumption and safety during operation (Kudra \& Mujumdar, 2009).

It is proposed to introduce contact sorption drying as a method to reduce the moisture content in coal fines by creating a mass concentration gradient between the wet coal and dry sorbent. The aim of this study was to investigate the possibility to dry fine and ultra-fine coal using porous ceramic as moisture sorbent. The investigation focusses on defining how the temperature, particle size variations and mixing ratio will influence the contact between the coal and ceramic and consequently the moisture transfer. The efficiency of the contact drying technique would lay in the possibility of separating the coal and ceramic and furthermore regenerate the ceramic for re-use. 


\section{Background}

Ceramic is an inorganic solid that is relatively cheap as many manufactures produce it from waste material (Lin et al., 2012). Ceramic is used as an adsorbent due to its permeability and extensive pore size distribution. It is specifically favoured due to its retention ability and the permeate flux it causes (Li et al., 2006). According to Lin et al. (2012) ceramic is unique as it is porous, yet has great mechanical and thermal stability making it suitable for industrial purposes.

Contact sorption drying takes place in three main stages as indicated in Figure 1. During the first stage the wet coal comes in contact with the dry ceramic and a small amount of moisture transfer takes place. This phase relies mainly on effective contact between the material and sorbent. The moisture is adsorbed unto the surface of the sorbent through diffusion and then penetrates through the pores of the sorbent. This set in motion the macro scale diffusion due to the large moisture concentration gradient between the wet coal and dry ceramic. The majority of the contact sorption drying takes place during the second stage and reaches a clear equilibrium where no major moisture transfer takes place. At the completion of the drying process, minor penetration and diffusion will take place between the sorbent and material leading to a very slow drying rate. Moisture transfer between sorbent-sorbent particles and material-material particles will result in minor fluctuations in the final equilibrium moisture content (Kudra \& Mujumdar, 2009).

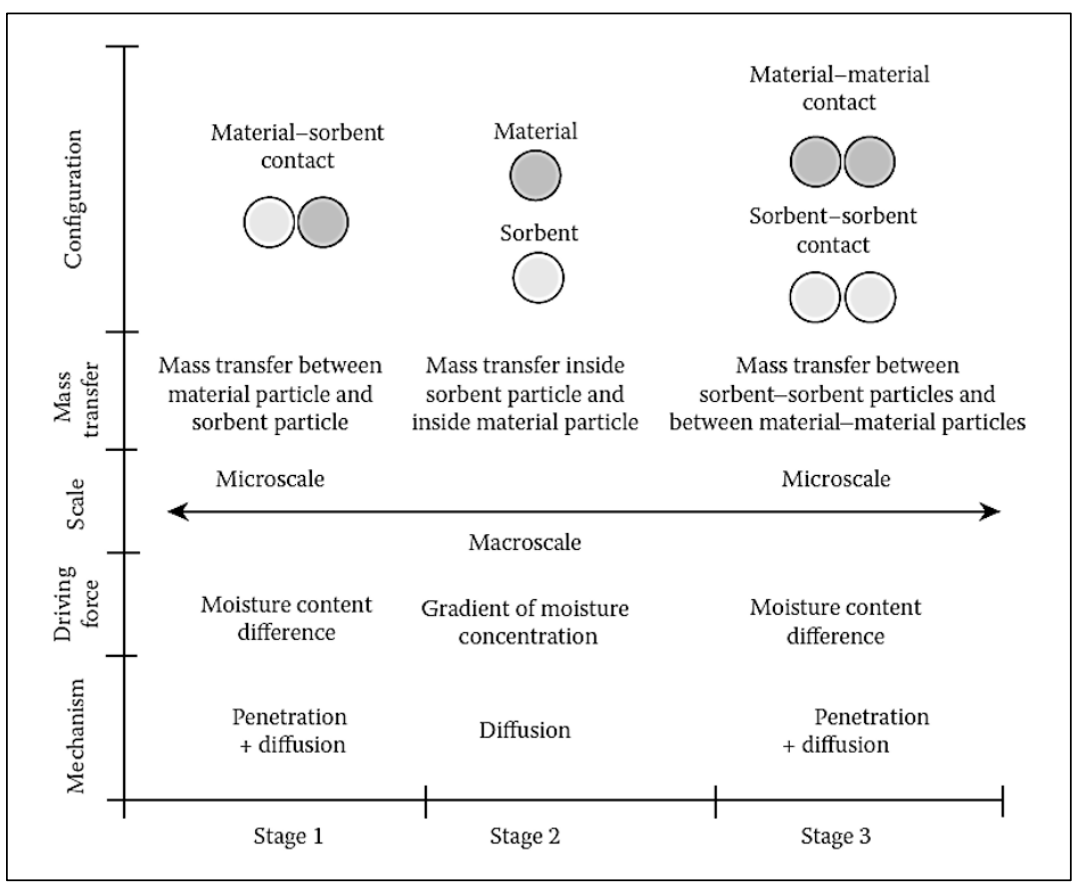

Figure 1. Drying mechanism for contact sorption drying (Kudra \& Mujumdar, 2009) 


\section{Experimental}

This report aims to define how the temperature, size variations and ratio will influence the contact between coal and ceramic for effective adsorption. The efficiency of contact sorption drying was tested on fine coal as well as ultra-fine coal.

\section{Equipment}

The experimental work was based on laboratory scale units to test the proof of concept and Figure 2 gives a layout for this contact sorption drying process. Firstly the drying process took place within the rotating adsorber, after which the loaded ceramic and dry coal were separated by screening. Finally the saturated ceramic was dried within a packed bed to be re-used in the contact sorption drying. The adsorber was designed to rotate the enclosed cylinder with a diameter of $8 \mathrm{~cm}$ at about three revolutions per minute to ensure sufficient contact between the coal and ceramic. The cylinder was specifically placed horizontally to prevent the coal and ceramic from separating due the large difference their particle size and density. Laboratory sieves were used to separate the saturated ceramic and dried coal before the ceramic was placed in a packed bed to be dried. Wet ceramic was easily separated from the dry coal and the packed bed dryer regenerated the ceramic to a point where it could be re-used. Note that only results from the rotary adsorber are discussed in this report.

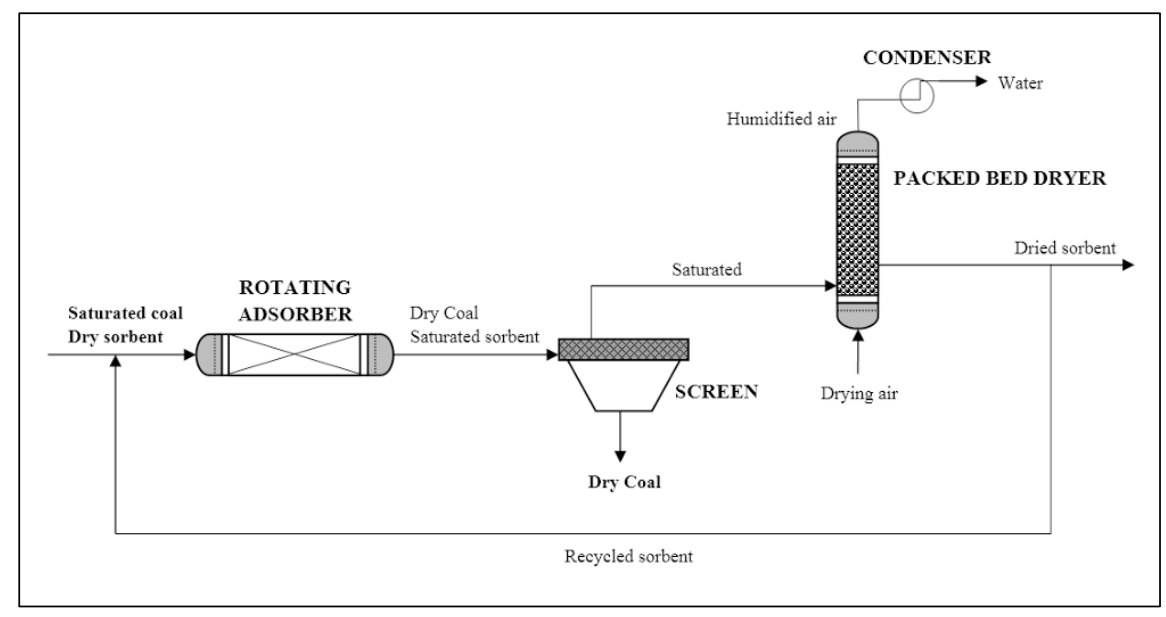

Figure 2. Diagram of contact sorption drying and regeneration process

\section{Material}

Coal from the Highveld coal field in South Africa was used in this study. The samples were initially left to dry in ambient air and thereafter crushed to a fine coal fraction of $+1 \mathrm{~mm}-2 \mathrm{~mm}$ and an ultra-fine coal fraction of smaller than $0.5 \mathrm{~mm}$. A sample splitter was used to produce uniform samples of $100 \mathrm{~g}$ each to obtain more repeatable experimental data. Afterwards the samples were drenched in water and filtered to a total moisture content of about $14-16 \% \%_{\mathrm{wt}}$ for the fine coal fraction and $18-25 \%_{\mathrm{wt}}$ for the ultra-fine coal fraction. Porous ceramic containing about $82-85 \%$ wt of Alumina oxide was used as an adsorbent to transfer water away from the coal. The test work was completed using ceramic spheres of between 6$10.5 \mathrm{~mm}$ and $12-20 \mathrm{~mm}$. 


\section{Results and discussion}

Fine coal was dried within the rotary adsorber and the moisture content of both the ceramic and coal was determined at various intervals. The experiment was conducted at $25^{\circ} \mathrm{C}$ and the material used included fine coal and ceramic with a particle size distribution of $+1-2 \mathrm{~mm}$ and $+6-10.5 \mathrm{~mm}$ respectively. Figure 3 shows that the moisture loss from the coal correlates with the moisture uptake in the ceramic spheres. The majority of the moisture transfer took place within the first 5 minutes indicating that the moisture within the bulk coal sample could rapidly be reduced from about $19 \%_{\mathrm{wt}}$ to $9 \%_{\mathrm{wt}}$. After the major moisture transfer, the drying rate slowed down significantly as the coal reached a level close to its final inherent moisture content. It was observed that towards the completion of the experiment that the coal adsorbed a small amount water again, but it was adsorbed by the ceramic again soon after. This phenomena occurred continually after the coal and ceramic reached equilibrium. Kudra \& Mujumdar (2009) states that these moisture fluctuations are referred to as stage 3 during the drying process. During this stage variations in the moisture content are due to the moisture transfer between sorbent-sorbent, material-material as well as sorbent-material particles. Initially the contact sorption drying took place in an enclosed container at static conditions, but it was found that there was a lot of vigorous fluctuation in the data. A rotary adsorber was introduced to ensure maximum contact between the coal and ceramic and Figure 4 shows the improvement in the data thereafter.

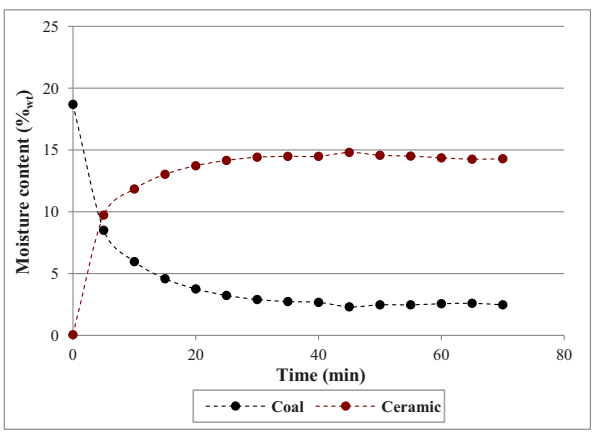

Figure 3. Moisture transfer during contact drying

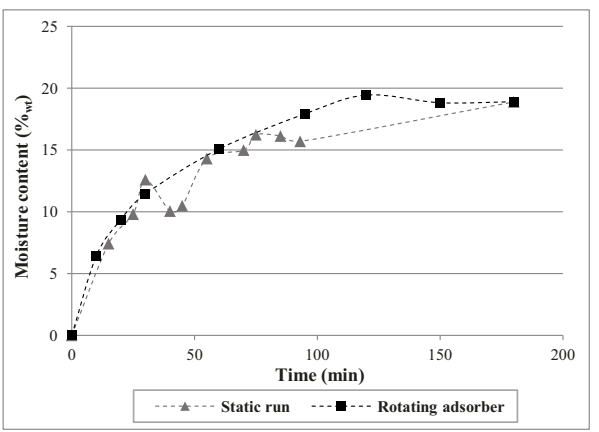

Figure 4. Static versus rotating adsorber

Ceramic spheres between size ranges of $+6-10.5 \mathrm{~mm}$ and $+12-20 \mathrm{~mm}$ were used to determine the difference in adsorption rate of moisture from ultra-fine coal samples at $25^{\circ} \mathrm{C}$. The results obtained from these two experimental runs are given in Figure 5. It was found that the smaller ceramic spheres had the ability to adsorb more moisture from the coal at a much faster rate, when compared to the larger ceramic particles. Asmatulu \& Yoon (2012) stated that finer particles attract and retain water mainly because they have a larger surface area compared to large particles. The larger surface area creates surface and capillary forces aiding in the adsorption process. It was therefore found that increasing the surface area by working with smaller ceramic, improved the contact during adsorption. However, it is important to keep the size ratio between the ceramic spheres and the fine coal particles large enough to aid in the separation thereof.

Figure 6 shows the difference in the sorption rate when fine and ultra-fine coal were dried. Ceramic with a size range of $+6-10.5 \mathrm{~mm}$ was used for adsorption at a temperature of $25^{\circ} \mathrm{C}$. The ultra-fine coal fraction had a higher moisture content and took much longer to dry compared to the fine coal particles. 
The fine coal showed a total of $8 \%_{\mathrm{wt}}$ moisture reduction in 14 minutes, while the ultra-fine particles took 87 minutes to reduce about $8 \%$ wt. The larger surface area of the ultra-fine coal creates more surface and capillary forces that prevent the moisture from leaving the finer coal particles (Asmatulu \& Yoon, 2012). Even though the ultra-fine particles took very long to dry, it must be noted that contact sorption drying was able to reduce the moisture content of the ultra-fine coal to its inherent moisture content. Moreover these results were achieved with just a rotary adsorber at atmospheric conditions without the need of expensive operating conditions. Bratton et al. (2012) also found that adsorbents were able to transfer water away from wet particles, irrespective of particle size.

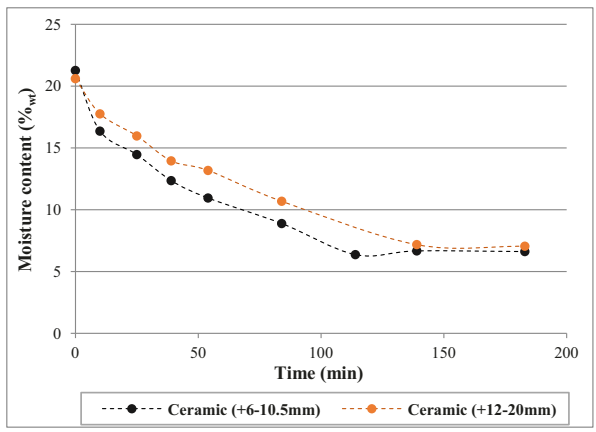

Figure 5. Variation in ceramic size

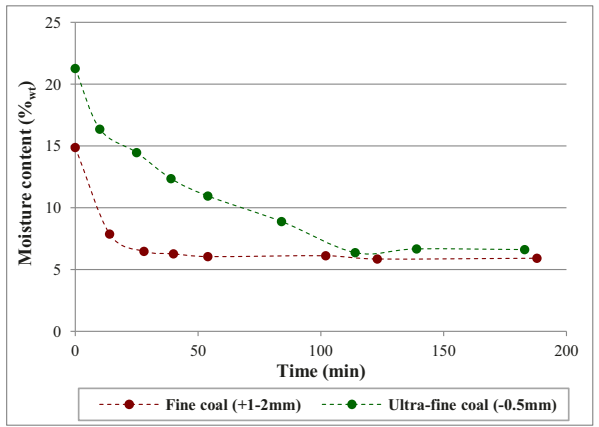

Figure 6. Drying rate of fine and ultra-fine coal

Fine coal samples of $100 \mathrm{~g}$ each were placed within the rotary adsorber at temperatures of $25^{\circ} \mathrm{C}, 40^{\circ} \mathrm{C}$ and $55^{\circ} \mathrm{C}$. Ceramic in a ratio of $1: 1$ were added to the one experiment, while the other experiment operated with more ceramic in a 1:3 ratio. The coal to ceramic ratio of 1:3 resulted in a faster dewatering rate compared to the feed ratio of $1: 1$. Increasing the amount of ceramic lead to more efficient contact between the coal and ceramic as more surface area of the ceramic was available for moisture transfer. Introducing elevated temperatures to the system didn't show a significant improvement in the drying rate. Figure 7 however illustrates that temperature had an effect on the final moisture content and a temperature of $55^{\circ} \mathrm{C}$ could reduce the moisture content by an additional $1 \%{ }_{\mathrm{wt}}$.

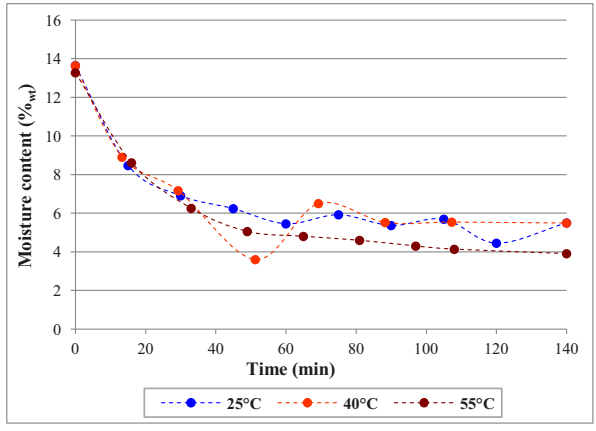

Figure 7. Ceramic to coal ratio of $1: 1$

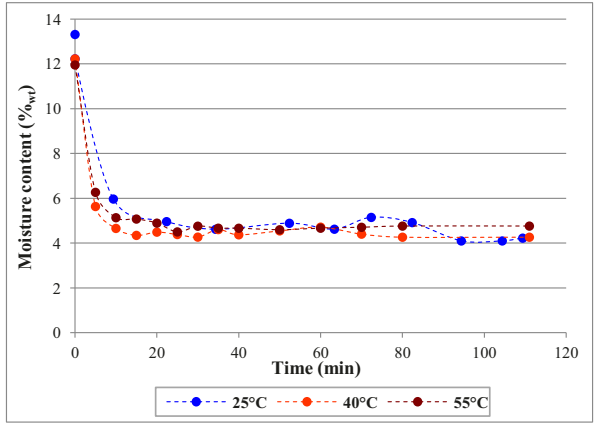

Figure 8. Ceramic to coal ratio of 1:3 
It can be seen in Figure 7 that the temperature had a larger effect on the coal moisture content towards the completion of the experiment. As a 1:1 ratio was already packed and had already reached optimum contact, the temperature could improve the transfer rate. This however had no noticeable effect in the first few minutes of drying. Figure 8 shows that changes in temperature didn't have an effect when optimal contact ratio between coal and ceramic were in place.

\section{Conclusion}

Ceramic was able to not only reduce the moisture content of fine coal, but of ultra-fine coal as well. The ceramic could reduce the moisture content irrespective of the size of coal dried. Working within a rotary adsorber ensured maximum contact between the coal and ceramic leading to more consistent results. Smaller ceramic had a larger surface area that allowed more efficient contact and consequently faster dewatering rates. The addition of more ceramic resulted in better contact with the wet coal and reduced the operating time quite significantly. In conclusion the results showed that improved contact between the coal and ceramic is the main driving force during adsorption drying.

\section{Bibliography}

Asmatulu, R. \& Yoon, R.H. 2012. Effects of Surface Forces on Dewatering of Fine Particles. (In Separation Technologies for Minerals, Coal and Earth Resources. Society of Mining, Metallurgy, and Exploration, Inc. (SME). p. 95-101).

Bratton, R., Ali, Z., Luttrell, G., Bland, R. \& McDaniel, B. 2012. Fine coal: Nano-drying technology. Coal Age, June: p. 50-57

Fourie, P.J.F., Van Der Walt, P.J. \& Falcon, L.M. 1980. The beneficiation offine coal bydensemedium. Journal of the South African Institute of Mining and Metallurgy:357-361

Kudra, T. \& Mujumdar, A.S. 2009. Advanced drying technologies. Second edition. p.169-184

Le Roux, M. An investigation into an improved method of dewatering fine coal. 2003.

Potchefstroom: NWU. (Dissertation - Masters).

Le Roux, M., Campbell, Q.P. 2003. An Investigation into an Improved Method of Fine Coal Dewatering. Minerals Engineering, 16(10):999-1003.

Li, W., Xing, W. \& Xu, N. 2006. Modeling of relationship between water permeability and microstructure parameter of ceramic membranes. Disalination, 192:340-345.

Lin, K-L., Lee, T-C., Chang, J-C. \& Lan, J-Y. 2012. Water absorption and retension of porous cermaics cosintered from water diatomite and catalyst. Environmental progress \& sustainable energy, 32(3):640-648.

Mangena, S.J., De Korte, G.J., McCrindle, R.I. \& Morgan, D.L. 2003. The amenability of some Witbank bituminous ultra fine coals to binderless briquetting. Fuel Processing Technology, 85(2004):1647-1662.

Reddick, J.F., Von Blottnitz, H. \& Kothuis, B. 2007. A cleaner production assessment of the ultrafine coal waste generated in South Africa. The Journal of The South African Institute of Mining and Metallurgy, 107:811-816. 